\title{
Algo más acerca de Francisco de Paula Jiménez Munuera y su abandono de la Scientia amabilis
}

\author{
M. LAÍNZ, S. J. \\ Avda. Hnos. Felgueroso, 25, E-33205 Gijón, España \\ E-mail: lainz@colegioinmaculada.es \\ Editor: N. Ibáñez
}

Recibido 4 septiembre 2011; Aceptado 13 septiembre 2011

\begin{abstract}
Another look at Francisco de Paula Jiménez Munuera and his departure from Scientia amabilis.- The correspondence between Francisco de Paula Jiménez Munuera, Spanish botanist from Cartagena (Spain) and Pius Font i Quer is revised. The internal circumstances and close details on the donation of the Jiménez Munuera herbarium to the Botany section of the Natural Sciences Museum of Barcelona, the future Botanic Institute, are revealed and analized.
\end{abstract}

Key words: Font i Quer; historical herbaria; Jiménez Munuera.

\begin{abstract}
Resumen
Algo más acerca de Francisco de Paula Jiménez Munuera y su abandono de la Scientia amabilis.- Se revisa la correspondencia entre Francisco de Paula Jiménez Munuera, botánico español de Cartagena, y Pius Font i Quer. Se revelan y analizan las circunstancias internas y los detalles más cercanos de la donación del herbario Jiménez Munuera a la Sección de Botánica del Museo de Ciencias de Barcelona, futuro Instituto Botánico.
\end{abstract}

Palabras clave: Font i Quer; herbarios históricos; Jiménez Munuera.

Al dar hace poco un vistazo a una larga carta en la que Pius Font i Quer -muy condescendientemente-, con fecha 17-I-1954, proseguía sus orientaciones al inquisitivo discípulo - cf. Laínz (1988)- tropiezo con las palabras referentes a Jiménez Munuera que transcribo a continuación: «Yo tuve correspondencia con él, allá por el año 1920»... Y, frente a cosas más o menos relativas al botanófilo por mí publicadas hace tiempo -cf. Laínz, 1994: 77-79, 1998: 326, 2001: 128-130, 2002: 169-170-, acto seguido envío un correo electrónico al director del Institut Botànic de Barcelona para interesarme por esa «correspon- dencia»; la cual, tras alguna pequeña orientación más precisa mía, rápidamente me llega del archivo del Institut, así como los muy amables ofrecimientos de su custodia -la Sra. Trinitat Prunera Pardell-, que me remite asimismo a lo ya hecho público por el propio Font Quer (1917: 257).

Dicha correspondencia hoy se reduce a una minuta -petitoria-de Font a Jiménez y seis cartas de Jiménez a Font -no poco ilustrativas en diversas direcciones-; conjunto que, a su vez, es ilustrado por lo que otras fuentes, positiva o negativamente, nos vienen a decir o nos inducen a sospechar. 
La minuta mencionada no tiene fecha - como tampoco, por excepción única, la respuesta de Jiménez a la correspondiente carta petitoria de Font-; pero las restantes cartas de Jiménez hacen evidente que la de Font se fechó el 20-VIII-1916. Las de su corresponsal consta -implícita o explícitamente- que son del 6-IX-1916, 29-XI-1916, 9-XII-1916, 20-I-1917, 12-II-1917 y 4-IV-1917. De la de Font, muy correcta ella, tan solo cabe destacar una línea: «He sabido que ha dejado V. el estudio de las plantas»... Jiménez, diecisiete días más tarde, le contesta como sigue.

Francisco de P. Jiménez

CARTAGENA

\section{Sr. D. P. Font Quer}

\section{Barcelona}

Muy Sr. mio: Ruego á V. encarecidamente que no atribuya á desatención la tardanza en contestar á su grata del 20 del pasado.

La proposición que V. me hace, honrosa por demás, para mí, me tiene perplejo $y$, verdaderamente, no sé todavía que contestarle. Desde luego me hubiera decidido á remitir á ese nuevo Museo mi modestísimo herbario, pero tengo un hijo que se resiste algo á desprenderse de esas plantas que representan un trabajo de más de quince años, y esto me obliga á una gestión preliminar cerca de mi antiguo amigo Cárlos Pau, antes de decidirme.

De todos modos le agradezco á V. vivamente la honra que me dispensa y á la que procuraré corresponder.

Soy de V. atento servidor

$$
\text { Q.B.S.M. }
$$

FdeP. Jiménez [rubricado]

Tras mes y medio largo, vuelve Jiménez a escribir, con alguna mayor detención (Fig. 1).

Francisco de P. Jiménez

CARTAGENA

29 Noviembre 1916

Sr. D. P. Font Quer

Barcelona

Muy distinguido Sr. mío: Supongo en poder de V. mi carta de 6 de Setiembre pasado.

Mis continuos viajes y perentorias ocupaciones, durante estos dos meses, me han impedido absolu- tamente ocuparme de mis aficiones, y esta causa ha hecho que se retrasase escribir á $V$.

Tenía que consultar con Pau, el caso probable de que necesite su ayuda y consejo, si me decidía á rehacer mi herbario; y este amigo, siempre complaciente, me brinda de nuevo su apoyo, al par que me elogia el trabajo que V. y otras personas están haciendo para crear el Museo de Cataluña.

Decidido, desde luego, á enviar ahi mis plantas, solo espero saber á nombre de quién las he de remitir, para hacer los paquetes.

Como condición, mejor dicho, como ruego, solo deseo que V. se interese con la dirección del Museo, para que oficialmente me acusen recibo del envio de las plantas, y a ser posible se conserven en paquete separado con la indicación de ser donativo mio. Esta pequeña vanidad sabrá $V$. disculparla, teniendo en cuenta que tengo un hijo, á quien ha de gustarle saber que el trabajo de su padre, mas ó menos modesto, se conserva en alguna parte.

Tengo el gusto de repetirme de $V$. atento servidor Q.B.S.M.

FdeP. Jiménez [rubricado]

Vemos que Pau, a quien ahora llama Jiménez «amigo» y no «antiguo amigo», sí contestó amabilísimamente a su consulta, en términos elogiosos para Font, etc.; y que la decisión está ya tomada, con leves condicionamientos del todo aceptables para los catalanes. Aunque ahí se habla también de «rehacer» el herbario, ya se pide incluso la dirección a la que se habrá de mandarlo..., «para hacer los paquetes». Resulta hoy evidente para todos que Pau metió a Font en el asunto; y, para mí, un poquito desazonante que no se disponga de las cartas en que se lo plantearía. Tras la que acabo de transcribir de Jiménez a Font, ya le fue posible a éste contestarle; y lo hizo, como vamos a ver, a vuelta de correo.

Paso a transcribir aquí la nueva carta de Jiménez a Font (Fig. 2), en la que por añadidura se hacen algunas cavilosas precisiones.

Francisco de P. Jiménez

CARTAGENA

9 Diciembre 1916.

Sr. D. P. Font Quer

Barcelona 


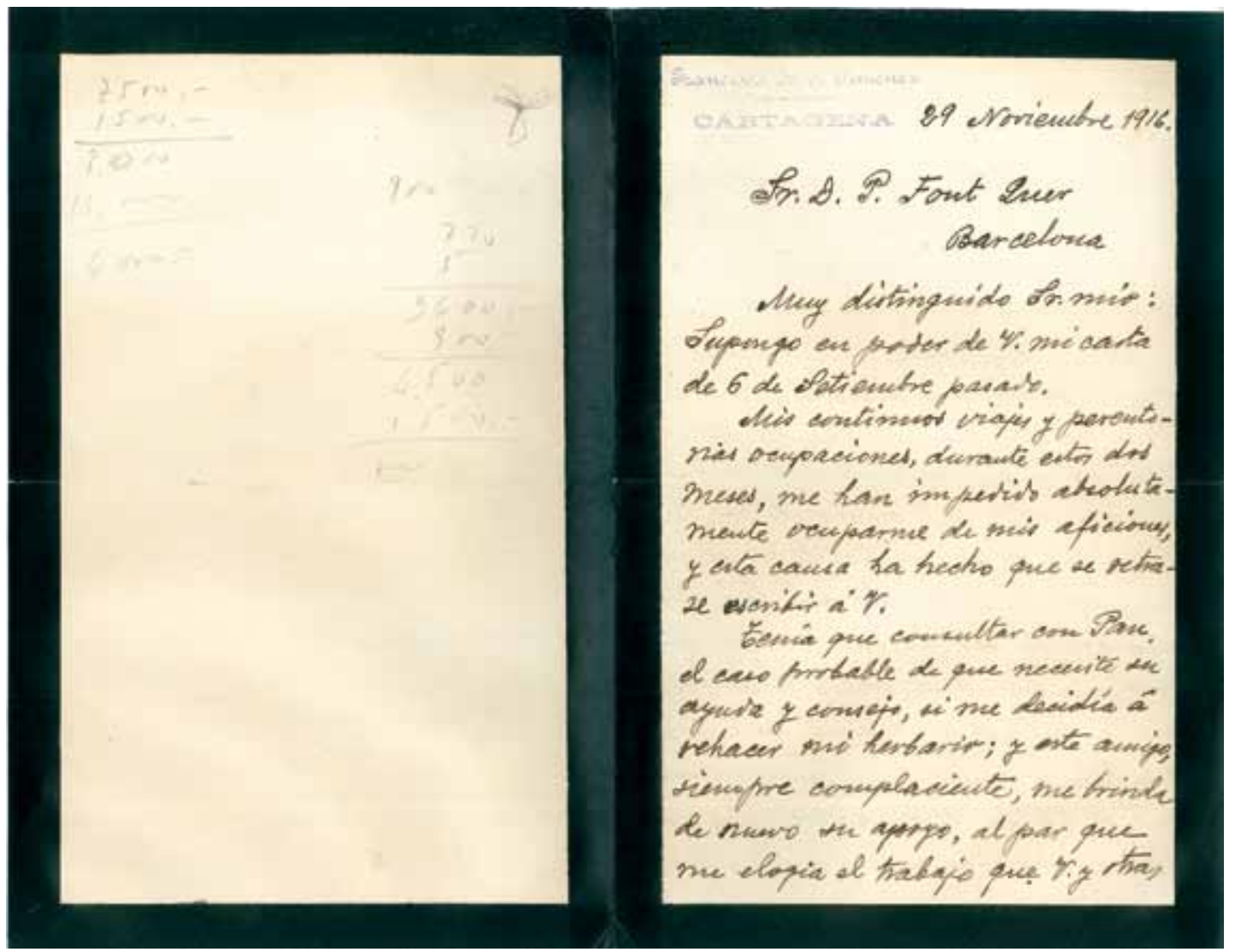

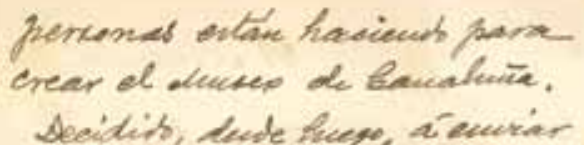
alí nis olautas, inle sparo kaker a numbe de quice las he de $x$ mitit, para haer ior pepueter.

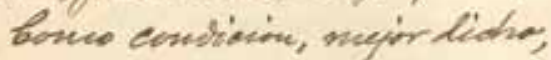

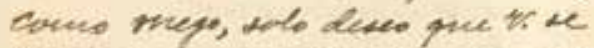
intoree don la diresdin Lederseo prin que fitielonute we acuses recibs del envir de her phe

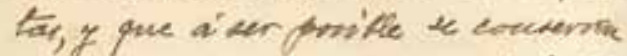
en paquete noanad son ta ientidacion de ver donation nevir. Lte

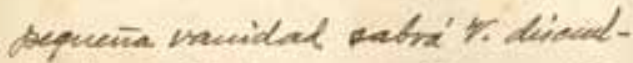
parla, tiviewh en suevela que tingo m hij, a' quviu ha de prostade valor

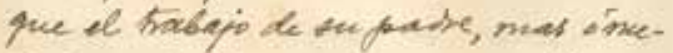

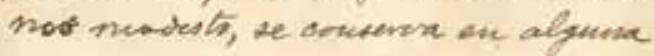

parte.

toupe ol puts de repatione de litento serorider 2.0.\%. .

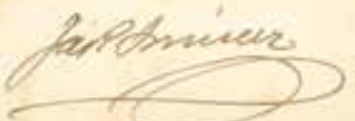

Figura 1. Carta de Jiménez Munuera a Font Quer del 29 noviembre de 1916. Archivo del Instituto Botánico de Barcelona. 
Muy distinguido Sr. mio: He recibido su muy grata carta del 4, y un pequeño detalle de ella, me obliga á molestar de nuevo su atención.

Dice $V$. que mis plantas «se colocarán en armario aparte», y esto me hace pensar si uno ú otros estaremos equivocados respecto á la importancia del herbario. Es seguro que cuando Pau le habló á $V$. de este asunto no dijo nada concreto respecto á su importancia, y yo quiero que no se sientan Vds. defraudados al recibir la remesa.

Mi herbario se refiere sola y exclusivamente á las plantas de Cartagena, cuya enumeración podrá $V$. ver en los dos folletos que por este correo le envío. Consta de unos setecientos ejemplares, que representan las plantas de esta comarca, con excepcion de algunas que se han inutilizado por los insectos y otras que por su dificil preparacion ha sido imposible conservar. Todas ellas las he recogido yo mismo y por eso aludía al trabajo empleado, durante muchos años.

Las pocas plantas que algunos amigos me han remitido á cambio, (bien pocas por cierto) no las he podido conservar.

Así pues, lo que ofrezco es, como digo, la colección completa de las plantas de Cartagena. Si esto modifica algo el interés del Museo por adquirirlas, le agradeceré a V. mucho que me lo haga saber, antes de empaquetar las plantas

Dispense V. la nueva molestia y disponga de su atento servidor

FdeP. Jiménez [rubricado]

Es claro que, de alguna forma, hubo de contestarle Font; lo que puede ya deducirse de las primeras líneas de la carta siguiente, con la que Jiménez - tras no poco ni poco meticuloso esfuerzo- daría por a punto de concluir la correspondencia...

Cartagena 20 Enero 1917

Sr. D. P. Font Quer

Barcelona

Muy distinguido Sr. mio: Por fin, después de cerca de un mes, he podido empaquetar mi herbario y remitirlo á Barcelona. Adjunto el talon-resguardo del ferro-carril, á nombre del Sr. Director del Museo, según la indicación de $V$.

Van las plantas empaquetadas por familias, tal como yo las conservaba aquí.
Cuando V. las reciba, hágame el favor de escribirme cuatro letras, para saber que han llegado en buen estado. También quisiera merecer de V. que, cuando le sobre tiempo, me diga en que forma las colocará entre las demás plantas, por si alguna vez visitara el Museo y pudiera verlas.

Crea $V$. que, aun cuando sea muy modesta la colección, me ha costado una verdadera emoción desprenderme de mis plantas. Si V., como naturalista, ha guardado muestras de sus excursiones, comprenderá esto perfectamente.

Saluda á V. muy afectuosamente

FdeP. Jiménez

[rubricado]

Pasó un día y otro día sin que a Jiménez le llegara el acuse de recibo pedido: prudentemente, se contuvo nada menos que durante veintitrés; al cabo de los cuales, decide romper sin más demora el silencio.

Cartagena, 12 Febrero 1917

Sr. D. P. Font Quer

Muy distinguido Sr. mio: Confirmo á V. mi carta del 20 del pasado, en la cual le enviaba talon del ferro-carril, de la remesa de mi herbario.

Como ha pasado ya cerca de un mes desde que se facturó aquí la caja en cuestión, me extraña que no me haya dado V. ninguna clase de noticias. Si no ha llegado aun á su poder, le ruego me lo comunique, para hacer la oportuna reclamacion á la compañia, pues no es creible que tarde un mes próximamente en llegar á esa el encargo.

Soy de V. atento servidor

FdeP. Jiménez [rubricado]

¡Cuál no sería su zozobra -el que espera, desesperacuando la respuesta de Font se hizo esperar hasta el $1^{\circ}$ de abril! Harto esclarecedora, exigió de Jiménez el muy cumplido pésame -con alguna peticionci1la...- que cierra la correspondencia disponible; que alguna otra hubo de haber entre Barcelona y Cartagena, se cae de su peso. 


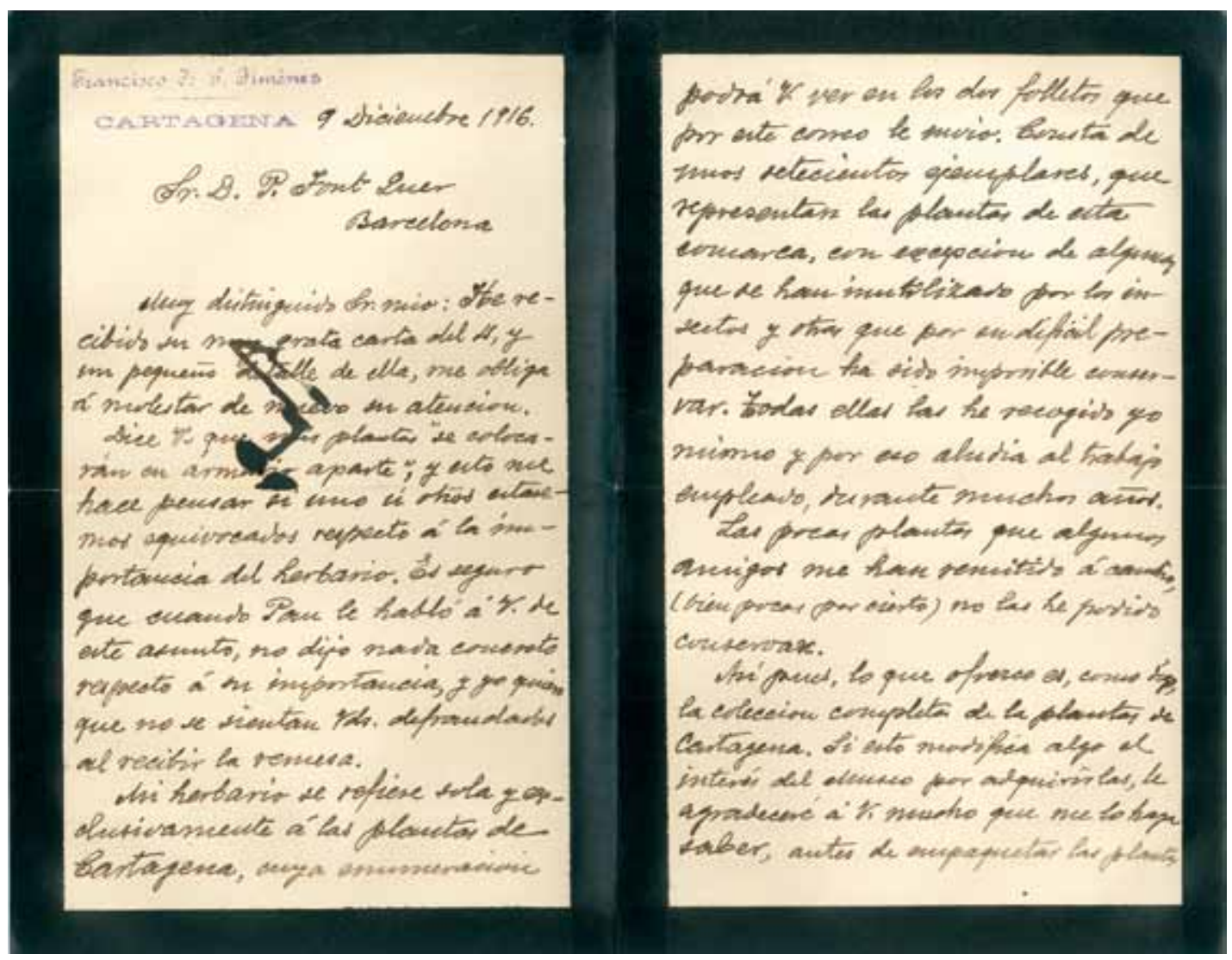

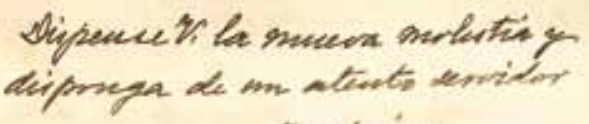

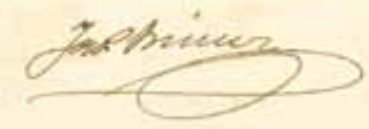

Figura 2. Carta de Jiménez Munuera a Font Quer del 9 de diciembre de 1916. Archivo del Instituto Botánico de Barcelona. 
FRANCISCO DE P. JIMÉNEZ

\section{CARTAGENA}

4 Abril 1917

Sr. D. P. Font Quer

Barcelona

Muy distinguido Sr. mio: Acabo de recibir su carta de $1^{\circ}$ del corriente, y me apresuro á manifestar á V. mi sentimiento por la pérdida de su Señor Padre, al mismo tiempo que le deseo á V. resignacion cristiana para soportar su natural dolor. Ley natural es, aunque no por eso menos dolorosa, que los hijos cierren los ojos de sus padres. Acompaño á $V$. en su justo dolor.

He tenido una verdadera satisfaccion en lo que me dice $V$. respecto a mis plantas: no están envenenadas, porque como dispongo de poco tiempo para dedicarlo á mis aficiones, y esa ope[ración] es algo engorrosa, siempre lo dejaba para otra ocasion, la cual no llegó nunca.

No olvide V., cuando sea ocasion, lo que me ofreció, respecto á una comunicacion oficial de ese Museo, pues esa pequeña vanidad es para dejarla de recuerdo á mi hijo, en vez del herbario, que tal vez él no pudiera conservar.

$Y$ á propósito de mi hijo, quisiera merecer de $V$. un favor: él es aficionado á los moluscos, y yo puedo ilustrarlo en sus dudas acerca de clasificacion: ¿no podría $V$. indicarme algun amigo de $V$. aficionado á las conchas, á quien pudiera yo enviar ejemplares de aquí, para que me indicara su determinacion? Si no es esto muy molesto para $V$., me atrevería á suplicarle que me contestara sobre este particular. Tal vez entre los naturalistas del Museo haya algun profesor de ese ramo de las Ciencias Naturales, y los ejemplares que yo pudiera enviarle, sirvieran para aumentar la coleccion del Museo ó la suya particular, si merecian la pena.

Dispense V. la libertad que me tomo y le ofrezco la reciprocidad para lo que de aqui se le ocurra.

Soy de V. afectísimo y atento servidor

FdeP. Jiménez [rubricado]

Sobre la enfermedad y defunción del Dr. Manuel Font i Balué, puede verse lo que Mateo (1996: 114) transcribe o extracta de la carta dirigida por el Dr. Font i Quer a Pau el 17-III-
1917 -por de pronto, excusa en ella un «largo silencio» y dice «Crea V. que he tenido dos meses bien tristes»-; me llegan últimamente del archivo del Institut Botànic de Barcelona, digitalizadas, tres cartas de Font a Pau; y en la precedente a la del 17 de marzo -del 24 de enero- leo: «Ayer recibí el talón para recoger las plantas de Jiménez; ya creí otra vez que se nos escapaban pues hacía tiempo que no sabía nada de ellas». En la que sigue, del 4 de abril, a poco de reanudar sus actividades habituales, repite: «No sé si le dije a $\mathrm{V}$. que las plantas de Jiménez Munuera llegaron hace tiempo. Así es, y me han gustado mucho por lo bien preparadas que están y porque son muy buenas algunas». De la del 29 de abril cabe aquí destacar: «Dentro de unos días escribiré al Sr. Gutiérrez de Ávila, por lo del Herbario que me decía V. El de Jiménez está todo envenenado, catalogado y ordenado». Son éstos detalles que -por incidentales, con evidencia- no hizo figurar Mateo (1996: 114, 115, 116) en sus extractos de las tres cartas dichas. Por cierto, lo del herbario Daniel Gutiérrez Martín -antes, farmacéutico de Olmedo (Valladolid)- se ve que no fue adelante, pues en Ávila estaba cuando en 1955 me pasé yo fugazmente por la céntrica farmacia heredada por un hijo del asimismo conocido corresponsal de Pau.

Queda claro por completo que no solo bendijo el de Segorbe la donación del herbario Jiménez a Barcelona sino que había sido él quien planificó al fundador futuro del Institut Botànic toda esa campaña de captaciones, aunque tal vez no pensaría por entonces en pasarse con armas y bagajes a proyectos un tanto incipientes. Hablan, sí, esas cartas -entre otras muchas cosas-, de adquisiciones de bibliografía extranjera por la que a Pau se le ve interesadísimo...

Aclaremos, como epílogo, que yo estoy en que Jiménez y Pau acabaron tirándose los trastos a la cabeza, por más que nos falten elementos de juicio del todo explícitos acerca de la ruptura. Parece que Pau estuvo interesado en hacerlos desaparecer de su epistolario, donde ahora echamos además de menos las cartas -elegantes, no es dudoso - de Jiménez a las que aluden las dirigidas por éste a Font el 6 de septiembre y 29 de noviembre de 1916. La certificada el 18-II-1911 - cf. Laínz (1994: 78-79)-, ¿pudo ser la última gota que desbordó las iras de un siempre temible Pau? ¿Por qué «censuró» 
éste - quién, si no- las cuartillas autobiográficas de Francisco Antonio Ibáñez Díaz - cf. Laínz (2002: 169-170)- a que por fin hube de referirme? Aunque las relaciones Jiménez - Pau fueron largamente muy distendidas - $c f$., v. gr., Laínz (1994: 68)-, más tarde se ve insatisfecho de la falta de amistosa correspondencia del segundo - tal vez porque ya el de Segorbe no esperaba mucho del otrora inapreciable colector dominguero y fautor muy cordial, a quien esa conducta pudo herirle no poco-; en todo caso, ahí está lo dicho por Font en su minuta: «He sabido que ha dejado V. el estudio de las plantas»...

No doy por imposible que alguna otra carta de Pau a Font -de momento, fuera de su alcanceacabe dando al director del Institut Botànic alguna mayor luz en asunto que se planteaba ya, mal, en los párrafos introductorios de Laínz (1994).

\section{REFERENCIAS BIBLIOGRÁFICAS}

Font-Quer, P. 1917. El Departament de Botànica del Museu. Junta de Ciències Naturals. Anuari 2: 251-260.

Laínz, M. 1988. Mi deuda con Font Quer. Miscellània Homenatge al Dr. Pius Font i Quer. Edicions de l'I.E.I., Lleida: 111-117.

Laínz, M. 1994. Algo sobre las relaciones de Pau con Francisco de Paula Jiménez Munuera. Anales Jard. Bot. Madrid 52: $67-79$.

Laínz, M. 1998. Algo sobre las relaciones de Pau con el P. Navás, S.J. Anales Jard. Bot. Madrid 56: 319-336.

Laínz, M. 2001. Algo sobre las relaciones de Pau con Ignacio -y Cándido- Bolívar. Anales Jard. Bot. Madrid 59: 125-134.

Laínz, M. 2002. Algunos otros documentos o indicaciones de utilidad para la historia de las Ciencias Naturales en España. Anales Jard. Bot. Madrid 60: 163-170.

Mateo, G. 1996. La correspondencia de Carlos Pau: medio siglo de historia de la Botánica española. Valencia. 